\title{
De Alemania y Austria a España: memorias posdictatoriales a debate
}

\author{
MaRIJE HrISTOVAI ${ }^{\star}$ \\ Universidad de Maastricht/CCHS-CSIC \\ José Carlos Marco Vega \\ FPU, Universidad Complutense de Madrid \\ JoHaNNa VOLLMEYER \\ Universidad Complutense de Madrid/Humboldt-Universität zu Berlin
}

Se puede hablar de la existencia de universales en los diferentes discursos de la memoria? ¿Qué papel desempeña la memoria en el proceso de construcción de la identidad? ¿Y el discurso historiográfico? ¿Es posible la memoria sin el olvido? Estas son sólo algunas de las preguntas con las que arrancó el curso de verano «Memorias controvertidas: España, Alemania y Austria», celebrado en San Lorenzo de El Escorial entre el 16 y el 20 de julio de 2012 y organizado por los profesores Arno Gimber (Universidad Complutense) y Georg Pichler (Universidad de Alcalá).

Más concretamente, el objetivo del curso consistió en analizar y comparar el papel desempeñado por la memoria en los discursos políticos, sociales y artísticos de España, Alemania y Austria, estados actualmente democráticos pese a estar profundamente marcados por un pasado dictatorial no muy lejano. Igualmente, se pretendió prestar especial atención a la importancia de las obras literarias y cinematográficas en el proceso de construcción del discurso de la memoria en cada uno de estos países. Además de la plantilla de investigadores, el curso contó con varios periodistas y miembros de asociaciones para la memoria que se sumaban a las discusiones por la tarde en forma de mesa redonda.

Como punto de partida, Manuel Reyes Mate propuso una serie de conceptos filosóficos relacionados con la memoria. Ma-

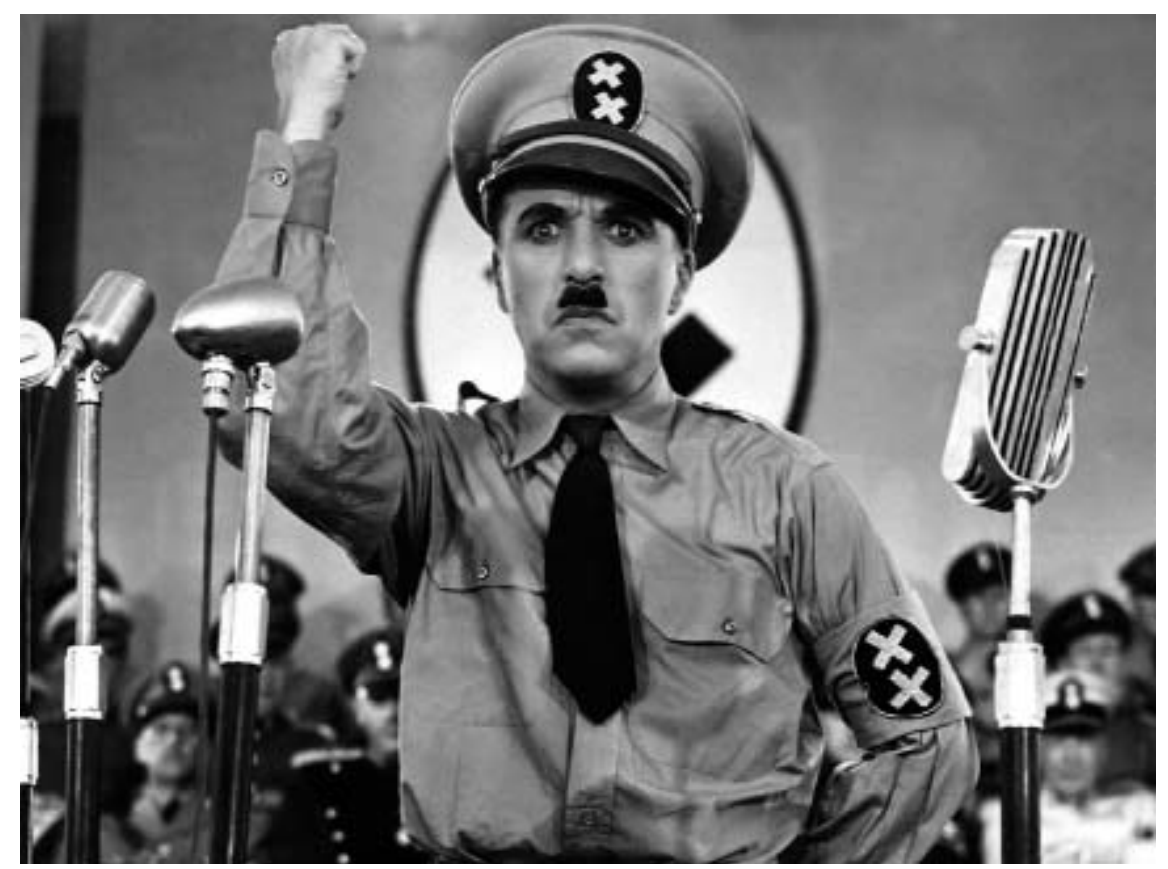

te subraya la dificultad de definir el concepto de la memoria, debido a su uso interdisciplinar, tratándose de un término manejado por historiadores, teóricos de la literatura, sociólogos, antropólogos, filósofos, científicos y teólogos. En cada una de estas disciplinas, la memoria significa siempre algo diferente. En el mismo campo de la filosofía, el concepto de memoria ha ido evolucionando a lo largo de los siglos. Así, mientras que en la Antigüedad y la Edad Media se considera que la memoria es conocimiento al cual sólo es posible acceder mediante el proceso de anamnesis, a partir sobre todo del siglo XIX el conocimiento es considerado como progreso, dejando de ser un simple reconocimiento. Es gracias a los trabajos de investigadores como Halbwachs, Bergson o Durkheim que los estudios sobre la memoria adquieren, a principios del siglo XX, un impulso hasta entonces desconocido.

En la mesa redonda de la sesión de la tarde, moderada por los organizadores del curso, el profesor Javier Fernández Vallina abordó, junto al filósofo Reyes Mate, el estudio del complejo historia-memoria. La pregunta que se planteó entre otras fue si podemos referirnos a la historia como realidad y a la memoria como interpela- 


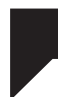

ción. Como es sabido, el discurso de la memoria es relativamente reciente, puesto que hasta finales del siglo XIX, el discurso historiográfico era considerado como el único legítimo para abordar la revisión del pasado al atribuírsele la capacidad de establecer una coincidencia mimética entre los hechos contados y los realmente acaecidos. El problema es que el discurso historiográfico nunca es objetivo, al contrario de lo que se creía en aquel momento. Además, no se puede identificar la realidad únicamente con los hechos, ya que también los 'no-hechos' forman parte de la realidad.

Apoyándose en Theodor W. Adorno y sus dudas ante la posibilidad de producir obras de arte después de Auschwitz, Reyes Mate insistió en el deber de la memoria. A raíz del Holocausto, historia y memoria empiezan a ir de la mano. En primer lugar, porque la falta de fuentes documentales obliga a los historiadores a echar mano del testimonio de los supervivientes para construir su discurso. En segundo lugar, porque sólo mediante la memoria, una colectividad puede dar una explicación y un sentido al presente, tal y como se desprende de la definición de memoria dada por Anne Wieviorka en marzo de 1999: «La mémoire, c'est le fait qu'une collectivité se souvienne de son passé et cherche à lui donner une explication au présent, à lui donner un sens». Pero ¿hasta qué punto puede el historiador confiar en dichos testimonios? Y si admitimos que en efecto la memoria no puede ser considerada de forma limitada
Según Gimber, recuerdo y olvido se encuentran

íntimamente relacionados: así, por ejemplo,

cuando una colectividad decide 'echar al

olvido' una serie de recuerdos traumáticos,

no está haciendo otra cosa más que pasar

página para no plantar cara al pasado.

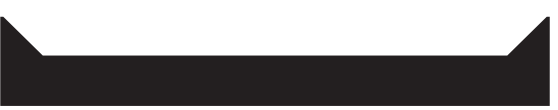

por los historiadores, ¿acaso no estamos atribuyendo a la historia una supremacía que no le corresponde?

Pero la memoria no sólo se transmite a través de testimonios sino que también se manifiesta en espacios, textos y soportes de otros tipos. Uno de los ejemplos citados durante el curso fue el de los monumentos históricos, susceptibles de sufrir resignificaciones sucesivas independientemente de su significado original. Quizá una de las manifestaciones más relevantes de este fenómeno es la cruz cristiana, considerada de forma muy negativa por los primeros cristianos y convertida poco más tarde en símbolo sagrado.

La resignificación de monumentos o lugares históricos pone de manifiesto que también el olvido desempeña una función esencial en la construcción del discurso de la memoria. El profesor Arno Gimber pro- puso a este respecto un análisis exhaustivo sobre el comportamiento dialéctico entre recuerdo y olvido en los procesos anamnésicos de revisión del pasado. Especialmente interesantes resultaron las alusiones, por parte de Gimber, a las manifestaciones del olvido en la literatura. Valgan como ejemplo el relato Funés el memorioso de José Luis Borges o la novela Austerlitz de W.G. Sebald.

Según Gimber, recuerdo y olvido se encuentran íntimamente relacionados: así, por ejemplo, cuando una colectividad decide 'echar al olvido' una serie de recuerdos traumáticos, no está haciendo otra cosa más que pasar página para no plantar cara al pasado. Sin embargo, muchos de estos recuerdos forzados al olvido se mantienen vivos en la memoria individual de miembros de ese colectivo, pudiendo salir más tarde a la luz. Es lo que Marcel Proust o Aleida Assmann denominan mémoire involontaire. Es precisamente eso lo que sucedió en Alemania a partir de mayo del 68, momento en el que, con la llamada Vergangenheitsbewältigung, queda al descubierto el trauma provocado por la Segunda Guerra Mundial, des-

prendiéndose así la capa del olvido que había enmudecido a la sociedad alemana durante la era Adenauer. En ocasiones, sin embargo, el olvido puede ser la respuesta a la fati- 
ga de memoria sufrida por una colectividad. El olvido y la memoria también fueron el tema de la exposición de Cecilia Dreymüller, en la que nos ofreció un breve recorrido por la literatura alemana después de la Segunda Guerra Mundial.

Después de haber sido presentada toda una serie de consideraciones teóricas generales sobre la memoria, el objetivo del curso fue el de comparar el funcionamiento de ésta en los tres países objeto de estudio, haciéndose especial énfasis en el tema de los marcos geográficos de la memoria colectiva. ¿Es la memoria solamente un asunto nacional? ¿Podemos hallar

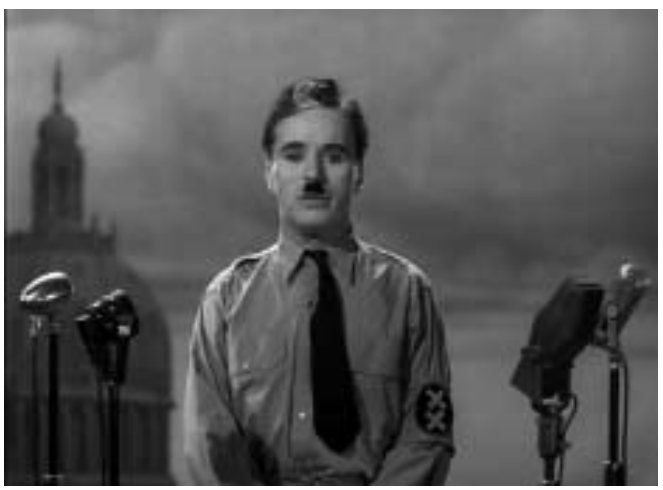

mecanismos y contenidos de memoria que superan los marcos nacionales? Después de comparar el caso alemán, español y austriaco, estas preguntas aparecieron con mucha frecuencia e intensidad durante los debates del curso. Por otro lado, este tema fue apuntado específicamente en las intervenciones de los filólogos Georg Pichler, Dieter Ingenschay, Luisa Juárez y el periodista Marco Schwartz.

Pichler, de origen austríaco y cuya aportación justifica la presencia de este país en el título del curso, centró su presentación en las especificidades de la memoria del austrofascismo (1933-1938), de la Segunda Guerra Mundial y del Holocausto en Austria. A pesar de lo específico del tema, Pichler presentó la historia de esta memoria 'nacional' dentro de un marco radicalmente transnacional. Por eso quizás, antes de adentrarse en la memoria controvertida de su país natal, Pichler nos introdujo en un viaje fotográfico por Rusia y el antiguo bloque soviético, señalando los espacios cotidianos que simbolizan tanto la memoria del viejo sistema como la del nuevo mundo después de 1989. En esta primera parte de la ponencia, pudimos comprobar cómo en el espacio urbano se so- lapan y contraponen diferentes capas de la memoria comunista, capitalista y zarista. Después de esta incursión por Rusia y el antiguo bloque soviético, Pichler centró su ponencia en la construcción de la memoria en un contexto internacional enfocado en Austria. Apoyándose en el ensayo From the House of the Dead: On Modern European Memory de Tony Judt (2005), Pichler señaló cómo el silencio en Austria se alineó con los silencios iniciales en otros países como Francia y Alemania. Fue el proceso de globalización de la

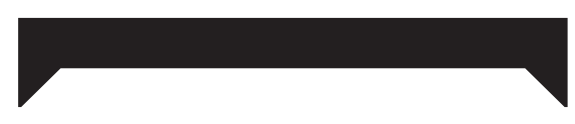

El plano transnacional nos ayuda

a redefinir el colectivo mnemónico

más allá de las fronteras nacionales

impuestas y señala precisamente

cómo la memoria resiste a tales marcos

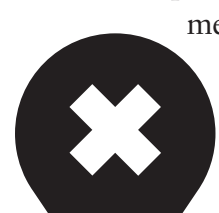

cia dictatorial. Vemos pues cómo a través de relatos literarios transnacionales, las memorias de diferentes dictaduras pueden compararse, converger y apropiarse unas a otras.

Esta línea de pensamiento se ejemplificó con la aportación del periodista Marco Schwartz, que ofreció su visión sobre las memorias alemana y española desde su perspectiva cosmopolita: hijo de judíos polacos emigrados a Colombia en los años 1920, Schwartz vivió una larga temporada en Nueva York y desde 1986 reside en Madrid. Claramente, las nuevas propuestas y desafíos en el campo de los estudios de la memoria giran en torno al entendimiento de los mecanismos de la memoria transnacional, como afirma también Ingenschay. El plano transnacional nos ayuda a redefinir el colectivo mnemónico más allá de las fronteras nacionales impuestas y señala precisamente cómo la memoria resiste a tales marcos preestablecidos.

A nuestro entender el tema de la memoria transnacional fue uno de los puntos fuertes del curso en su totalidad. Pese a que Alemania, Austria y España, por sus experiencias dictatoriales tan distintas, tal vez no serían los preestablecidos. primeros países que uno elegiría para llevar a cabo un ejercicio comparativo, el marco transnacional utilizado permite abrir perspectivas sobre la memoria que nos ayudan a pensar más allá del afán comparativo y sus posibles conclusiones dudosas.

Aparte de las líneas propuestas por Ingenschay y Schwartz, también se debatió

memoria del Holocausto y el contexto memorialístico de la Unión Europea los que propagaron otra manera de enfrentarse a este pasado complejo.

La memoria del Holocausto es considerada como el símbolo global de la injusticia y la inhumanidad por excelencia. Luisa Juárez señaló la trascendencia y la globalización del Holocausto como icono de la memoria en la literatura estadounidense. Asimismo, el profesor Ingenschay señaló que la dictadura argentina y la práctica de la desaparición forzada también se han convertido en una referencia internacional que se enlaza con otras memorias. En su ponencia explicó mediante el análisis detallado de algunas novelas españolas y alemanas cómo en estos últimos países se propone un acercamiento al caso argentino a través de la propia experien- la apropiación de un lenguaje común de derechos humanos y de justicia transicional tras las exhumaciones de fosas comunes en España. El curso presentó así una forma más 'práctica' de abordar los estudios de memoria, llevándonos a considerar cómo deben ser tratadas, tanto legal como políticamente, las exhumaciones de las víctimas del Franquismo en la España de hoy. de Emilio Silva se plantearon entre otras las siguientes preguntas: ¿En qué consiste la labor de los científicos y asociaciones en este campo? ¿Cuál es la situación actual de este trabajo, que conlleva un valor científico y a su vez humano muy alto?

Tanto Ferrándiz como Silva hicieron hincapié en que las exhumaciones deben ser contextualizadas en un marco de derechos humanos universales, lo cual las sacaría En las ponencias de Francisco Ferrándiz y 
